\title{
SIMULTANEOUS OPTIMIZATION OF SEMI- ACTIVE QUARTER CAR SUSPENSION PARAMETERS USING TAGUCHI METHOD AND GREY RELATIONAL ANALYSIS
}

\author{
Devdutt $^{1}$ and M.L. Aggarwal ${ }^{2}$ \\ ${ }^{1,2}$,Department of Mechanical Engineering, YMCA University of Science \& Technology, \\ Faridabad, India
}

\begin{abstract}
In present paper, a methodology is presented related to the optimization of semi-active quarter car model suspension parameters having three degrees of freedom, subjected to bump type of road excitation. Influence of primary suspension stiffness, primary suspension damping, secondary suspension stiffness and secondary suspension damping are studied on the passenger ride comfort, taking root mean square (RMS) values of passenger seat displacement and settling time into account. Semi-active quarter car model assembled with magneto-rheological (MR) shock absorber is selected for optimization of suspension parameters using Taguchi method in combination with Grey relational analysis. Confirmatory results with simulation run indicates that the optimized results of suspension parameters are helpful in achieving the best ride comfort to travelling passengers in terms of minimization of passenger seat displacement and settling time values.
\end{abstract}

\section{KEYWORDS}

Quarter car model, MR shock absorber, Passenger ride comfort, Taguchi method, Grey relational analysis, Parameter optimization

\section{INTRODUCTION}

Passenger ride comfort is a major requirement in modern vehicles during its travelling period over different road profiles which need to be considered during design and development phase. Basically, road induced vibrations transmitted from vehicle tyres to passenger seat are responsible for harmful effects on the passenger health as well on vehicle parts. Usually, passenger ride comfort is characterized by the seat acceleration, seat displacement and seat settling time response respectively. With the advancement in technology, suspension system concept has developed from passive to semi-active and active suspension type. In present scenario, passive suspension system is still used in vehicle as well as in seat suspensions and dominating the automotive sector due to its low cost and assembly of simple parts such as passive or uncontrollable shock absorber and conventional spring [1-2]. But its performance is poor in terms of passenger ride comfort and vehicle handling issues. While active suspension system can provide best ride comfort and road holding ability using the latest available technology, supplying required damping force from externally connected energy source but its cost and complicated sensors and actuators makes this concept applicable in limited vehicles [3-4]. 
Semi-active suspension system can deliver better performance than passive suspension and less costly as well as technically adaptable with magneto-rheological (MR) and electro-rheological (ER) shock absorbers compared to active type [5-6]. Feasibility study of electro-rheological and magneto-rheological shock absorbers in semi-active suspension system has been studied by many researchers [7-8]. MR shock absorbers poses many attractive characteristics in terms of requirement of very less power for its working, rapid response time of few milliseconds as well as not affected by temperature variations. Since MR shock absorbers shows highly nonlinear dynamic and hysteretic nature during working, this makes the development of proper controller necessary for its utilization practically. Various parametric and non-parametric models have been developed for real use of MR shock absorbers which can match the dynamic behavior of these shock absorbers [9-13]. The used experimental results of MR shock absorber as well as fuzzy controller design in present research work can be found in [14].

In past, some studies have been performed related to the optimization of suspension system parameters. A.F. Naude et. al [15] developed vehicle simulation programme for optimization of damper characteristics of 22 ton three axle vehicle. The leap-frog optimisation algorithm for constrained problems (LFOPC) was integrated with multi-body dynamics simulation code (Vehsim2d) for optimization purpose. Anil Shirahatt et. al [16] applied genetic algorithm (GA) and compared with simulated annealing (SA) technique to select the passive and active suspension parameters for a full car model. A number of objectives were selected to fulfill passenger ride comfort and vehicle handling issues while the vehicle travels through sinusoidal road input. P.Senthil kumar et. al [17] used Taguchi method for optimum design of passenger friendly vehicle suspension. MSC ADAMS software was selected to perform simulation work under bump type of road displacement for passive quarter car model. ANOVA method was applied to observe the effect of input parameters such as stiffness of spring and damping coefficient of shock absorber on the passenger seat displacement and settling time. R. Kalidas et. al [18] used passive full car model for optimization of spring stiffness and damping co-efficient of shock absorbers using Taguchi approach. Taguchi method was selected to obtain optimum parameters of suspension system using design of experiments. MSC ADAMS software was used for simulation and confirmation analysis for seat displacement and settling time respectively.

In literature, most of the available research work is related to the development of new control algorithms or comparative analysis of different control algorithm strategies to achieve better ride comfort and vehicle handling issues, taking advantages of MR shock absorbers using numerical simulation work. There is very little research work available in the direction of optimization of semi-active quarter car suspension parameters to enhance its performance capability to provide better ride comfort experience to travelling passengers. The aim of present paper is to optimize the suspension system parameters to achieve the best ride comfort for travelling passengers, taking the influence of shock absorber damping characteristics and spring characteristics in the quarter car model with three degrees of freedom. For simulation purpose, semi-active quarter car model assembled with MR shock absorber in primary suspension system is considered while secondary suspension system is assembled with passive shock absorber. Simulation results in terms of RMS displacement and settling time of passenger seat is used for optimization of suspension parameters using Taguchi method and Grey relational analysis.

\section{SEMI-ACTIVE QUARTER CAR MODEL}

Figure 1 shows nonlinear semi-active quarter car model with three-degrees-of-freedom. This model is very useful for the analysis of vertical movement of assembled parts because of its design simplicity and rapid result generation capability. Three degrees of freedom of considered model include: vertical displacement motion of passenger seat $\left(z_{1}\right)$, sprung mass $\left(z_{2}\right)$ and 
unsprung mass $\left(z_{3}\right)$ respectively whereas $z_{r}$ is the displacement of tyre of moving vehicle on the road. The damping force generated by MR shock absorber is denoted by $F_{M R}$ during current supplied stage to it. This nonlinear quarter car model can provide graphical data using simulation work and mathematical values can be calculated related to passenger seat displacement for analysis purpose. The constant values are selected for passenger seat mass $\left(\mathrm{m}_{1}=75 \mathrm{~kg}\right)$, sprung mass $\left(\mathrm{m}_{2}=320 \mathrm{~kg}\right)$ and unsprung mass $\left(\mathrm{m}_{3}=40 \mathrm{~kg}\right)$ respectively for simulation work while the selected parameters for optimization purpose are given in Table 1.

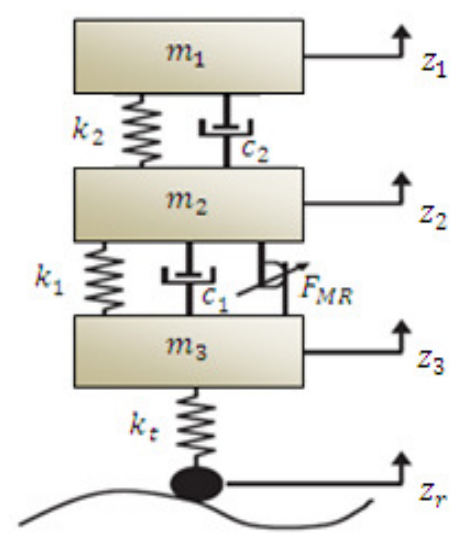

Figure 1. Semi-active quarter car model

The equations of vertical motions of passenger seat, sprung mass and unsprung mass for semiactive quarter car model can be derived using Newton's second law of motion as follows:

$\mathrm{m}_{1} \ddot{\mathrm{z}}_{1}+\mathrm{c}_{2}\left(\dot{\mathrm{z}}_{1}-\dot{\mathrm{z}}_{2}\right)+\mathrm{k}_{2}\left(\mathrm{z}_{1}-\mathrm{z}_{2}\right)=0$

$\mathrm{m}_{2} \ddot{\mathrm{z}}_{2}-\mathrm{c}_{2}\left(\dot{\mathrm{z}}_{1}-\dot{\mathrm{z}}_{2}\right)-\mathrm{k}_{2}\left(\mathrm{z}_{1}-\mathrm{z}_{2}\right)+\mathrm{c}_{1}\left(\dot{\mathrm{z}}_{2}-\dot{\mathrm{z}}_{3}\right)+\mathrm{k}_{1}\left(\mathrm{z}_{2}-\mathrm{z}_{3}\right)+\mathrm{F}_{\mathrm{MR}}=0$

$\mathrm{m}_{3} \ddot{\mathrm{z}}_{3}-\mathrm{c}_{1}\left(\dot{\mathrm{z}}_{2}-\dot{\mathrm{z}}_{3}\right)-\mathrm{k}_{1}\left(\mathrm{z}_{2}-\mathrm{z}_{3}\right)+\mathrm{k}_{\mathrm{t}}\left(\mathrm{z}_{3}-\mathrm{z}_{\mathrm{r}}\right)-\mathrm{F}_{\mathrm{MR}}=0$

\section{Taguchi Method for Suspension System Parameter Optimization}

Taguchi developed the orthogonal array method to study the systems in a more convenient and rapid way, whose performance is affected by different factors when the system study become more complicated with the increase in the number of factors. This method can be used to select best results by optimization of parameters with a minimum number of test runs. Application of Taguchi method can support significantly to achieve the best results out of various tests by selection of optimum combination of different factors. Final product quality can be improved ranging from industrial products to service sector in terms of process optimization, product design and system analysis [19-22]. The steps followed for suspension parameter optimization using Taguchi method in present study related to minimization of RMS passenger seat displacement (PSD) and settling time (ST) values are as follows:

1. Suspension system parameters selection.

2. Level assignment to each suspension parameter.

3. Taguchi orthogonal array selection.

4. Simulation work using quarter car model.

5. Calculation of RMS passenger seat displacement and settling time values.

6. Calculation of $\mathrm{S} / \mathrm{N}$ ratios using obtained RMS PSD and ST values.

7. Data analysis and selection of optimum levels of process parameters. 
8. Final Experimental / Simulation work, taking obtained suspension parameter values.

Simulation results are used to determine the corresponding values in terms of signal-to-noise $(\mathrm{S} / \mathrm{N})$ ratio for each run. It projects the performance of each test run depending on the obtained $\mathrm{S} / \mathrm{N}$ ratio. Basically, three types of $\mathrm{S} / \mathrm{N}$ ratios are used in Taguchi method such as: lower is better (LB), higher is better (HB) and nominal is best (NB). Since the lower values of passenger seat displacement and displacement settling time are prime requirement to achieve passenger ride comfort and safety, thus in present work, $\mathrm{S} / \mathrm{N}$ ratio with a lower is better characteristics is selected as expressed below:

Lower is better (LB) characteristic:

$$
\eta=\frac{S}{N_{L B}}=-10 \log \left(\frac{1}{r} \sum_{i=1}^{r} y_{i}^{2}\right)
$$

where:

$\mathrm{y}_{\mathrm{i}}=$ value of measured performance characteristics out of $\mathrm{i}$ observations.

$\mathrm{r}=$ number of run in experimental work.

Table 1 Suspension parameters with their levels for quarter car model

\begin{tabular}{clccc}
\hline \multirow{2}{*}{ Symbol } & \multicolumn{2}{c}{ Suspension Parameter } & \multicolumn{3}{c}{ Levels } \\
\cline { 3 - 5 } & & 1 & 2 & 3 \\
\hline A & Primary suspension stiffness $\left(\mathrm{k}_{1}\right)[\mathrm{N} / \mathrm{m}]$ & 26000 & 28000 & 30000 \\
B & Primary suspension damping $\left(\mathrm{c}_{1}\right)[\mathrm{N} / \mathrm{m} / \mathrm{s}]$ & 1200 & 1400 & 1600 \\
C & Secondary suspension stiffness $\left(\mathrm{k}_{2}\right)[\mathrm{N} / \mathrm{m}]$ & 9000 & 9200 & 9400 \\
D & Secondary suspension damping $\left(\mathrm{c}_{2}\right)[\mathrm{N} / \mathrm{m} / \mathrm{s}]$ & 700 & 800 & 900 \\
\hline
\end{tabular}

\subsection{Selection of Suspension parameters and Orthogonal array}

In this study, primary suspension MR shock absorber damping, spring stiffness as well as secondary suspension shock absorber damping and spring stiffness are selected as parameters for optimization purpose as shown in Table 1 while the bump type of road excitation responsible for vibration generation is shown in Figure 2. The orthogonal array (L9) selected to determine the optimum suspension parameters are shown in Table 2. Each suspension parameter is written in a column whereas the total combination of all four suspension parameters is having nine independent rows. Therefore, total nine simulation runs are required in present work to study the combination of entire suspension parameters influence using L9 orthogonal array.

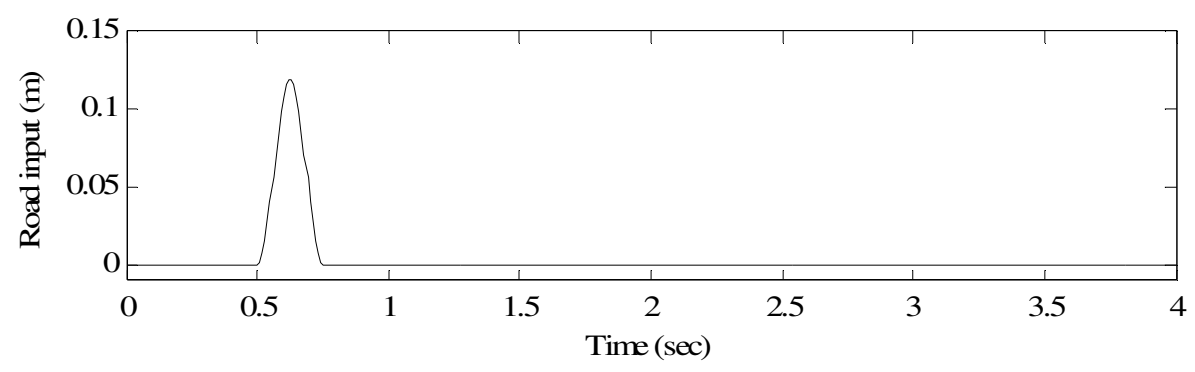

Figure 2. Bump type road excitation 
Table 2 Orthogonal array of Taguchi L9

\begin{tabular}{|c|c|c|c|c|}
\hline Run No. & A & B & C & D \\
\hline 1 & 1 & 1 & 1 & 1 \\
\hline 2 & 1 & 2 & 2 & 2 \\
\hline 3 & 1 & 3 & 3 & 3 \\
\hline 4 & 2 & 1 & 2 & 3 \\
\hline 5 & 2 & 2 & 3 & 1 \\
\hline 6 & 2 & 3 & 1 & 2 \\
\hline 7 & 3 & 1 & 3 & 2 \\
\hline 8 & 3 & 2 & 1 & 3 \\
\hline 9 & 3 & 3 & 2 & 1 \\
\hline
\end{tabular}

\subsection{ANALYSIS OF SIGNAL- TO-NOISE (S/N) RATIO}

Since, improvement in the quality of results are related to minimization of passenger seat displacement and settling time respectively, thus the equation used for mathematical calculation of S/N ratio is "lower is better" as per objective requirement. The calculated mean $\mathrm{S} / \mathrm{N}$ ratio for displacement and settling time for semi-active quarter car system is Table 3 as obtained by performing nine simulation runs.

Table $3 \mathrm{~S} / \mathrm{N}$ ratios of simulation results for Semi-active quarter car model in terms of RMS Displacement and Displacement Settling Time

\begin{tabular}{|c|c|c|c|c|c|c|c|c|}
\hline \multirow{2}{*}{ Run No. } & \multicolumn{4}{|c|}{ Parameters } & \multirow{2}{*}{$\begin{array}{c}\begin{array}{c}\text { RMS } \\
\text { displacement }\end{array} \\
{[\mathrm{m}]} \\
\end{array}$} & \multirow{2}{*}{$\begin{array}{c}\mathrm{S} / \mathrm{N} \\
\eta_{\mathrm{i}}(\mathrm{i}=1-9) \\
{[\mathrm{dB}]}\end{array}$} & \multirow{2}{*}{$\begin{array}{c}\begin{array}{c}\text { Settling } \\
\text { Time }\end{array} \\
\text { [sec] } \\
\end{array}$} & \multirow{2}{*}{$\begin{array}{c}\mathrm{S} / \mathrm{N} \\
\eta_{\mathrm{i}}(\mathrm{i}=1-9) \\
{[\mathrm{dB}]}\end{array}$} \\
\hline & A & B & $\mathrm{C}$ & D & & & & \\
\hline 1 & 26000 & 1200 & 9000 & 700 & 0.024 & 16.198 & 2.296 & -3.610 \\
\hline 2 & 26000 & 1400 & 9200 & 800 & 0.022 & 16.536 & 2.208 & -3.439 \\
\hline 3 & 26000 & 1600 & 9400 & 900 & 0.021 & 16.882 & 1.850 & -2.671 \\
\hline 4 & 28000 & 1200 & 9200 & 900 & 0.024 & 16.216 & 2.260 & -3.541 \\
\hline 5 & 28000 & 1400 & 9400 & 700 & 0.023 & 16.383 & 2.198 & -3.421 \\
\hline 6 & 28000 & 1600 & 9000 & 800 & 0.022 & 16.676 & 2.060 & -3.139 \\
\hline 7 & 30000 & 1200 & 9400 & 800 & 0.025 & 15.986 & 2.516 & -4.006 \\
\hline 8 & 30000 & 1400 & 9000 & 900 & 0.023 & 16.345 & 2.188 & -3.400 \\
\hline 9 & 30000 & 1600 & 9200 & 700 & 0.023 & 16.421 & 2.126 & -3.275 \\
\hline
\end{tabular}

RMS displacement $\mathrm{S} / \mathrm{N}$ ratio total mean value $=16.405 \mathrm{~dB}$

Settling time $\mathrm{S} / \mathrm{N}$ ratio total mean value $=-3.389 \mathrm{~dB}$

The calculated mean $\mathrm{S} / \mathrm{N}$ ratios for selected suspension parameters related to semi-active quarter car model with three degrees of freedom for defined levels i.e. from Level 1 to Level 3 in terms of mean RMS displacement and mean settling time values are written in Table 4. S/N plots for mean RMS PSD and mean ST values are presented in Figure 3 and Figure 4 respectively, helpful in selection of optimum combination of suspension parameters as A1B3C3D3 having largest $\mathrm{S} / \mathrm{N}$ ratios for individual suspension parameters. 
International Journal of Recent advances in Mechanical Engineering (IJMECH) Vol.4, No.1, February 2015

Table 4 Mean S/N ratios [dB] of Parameters for Semi-active Quarter car model

\begin{tabular}{|c|c|c|c|c|c|c|c|c|}
\hline \multirow{3}{*}{ Parameters } & \multicolumn{4}{|c|}{ RMS Displacement (m) } & \multicolumn{4}{|c|}{ Settling Time (sec) } \\
\hline & \multicolumn{3}{|c|}{ Level } & \multirow{2}{*}{ Max-Min } & \multicolumn{3}{|c|}{ Level } & \multirow{2}{*}{ Max-Min } \\
\hline & 1 & 2 & 3 & & 1 & 2 & 3 & \\
\hline $\mathrm{A}$ & 16.539 & 16.425 & 16.251 & 0.288 & -3.24 & -3.367 & -3.561 & 0.321 \\
\hline B & 16.133 & 16.421 & 16.66 & 0.527 & -3.383 & -3.42 & -3.028 & 0.392 \\
\hline $\mathrm{C}$ & 16.406 & 16.391 & 16.417 & 0.026 & -3.383 & -3.418 & -3.366 & 0.052 \\
\hline D & 16.334 & 16.399 & 16.481 & 0.147 & -3.435 & -3.528 & -3.204 & 0.324 \\
\hline
\end{tabular}
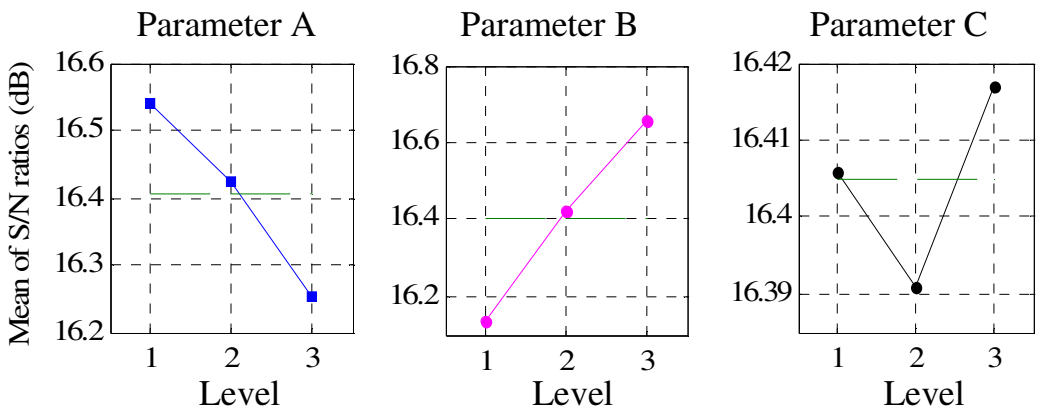

Parameter D

Figure 3. Effect of suspension parameters on RMS displacement S/N Ratio plots
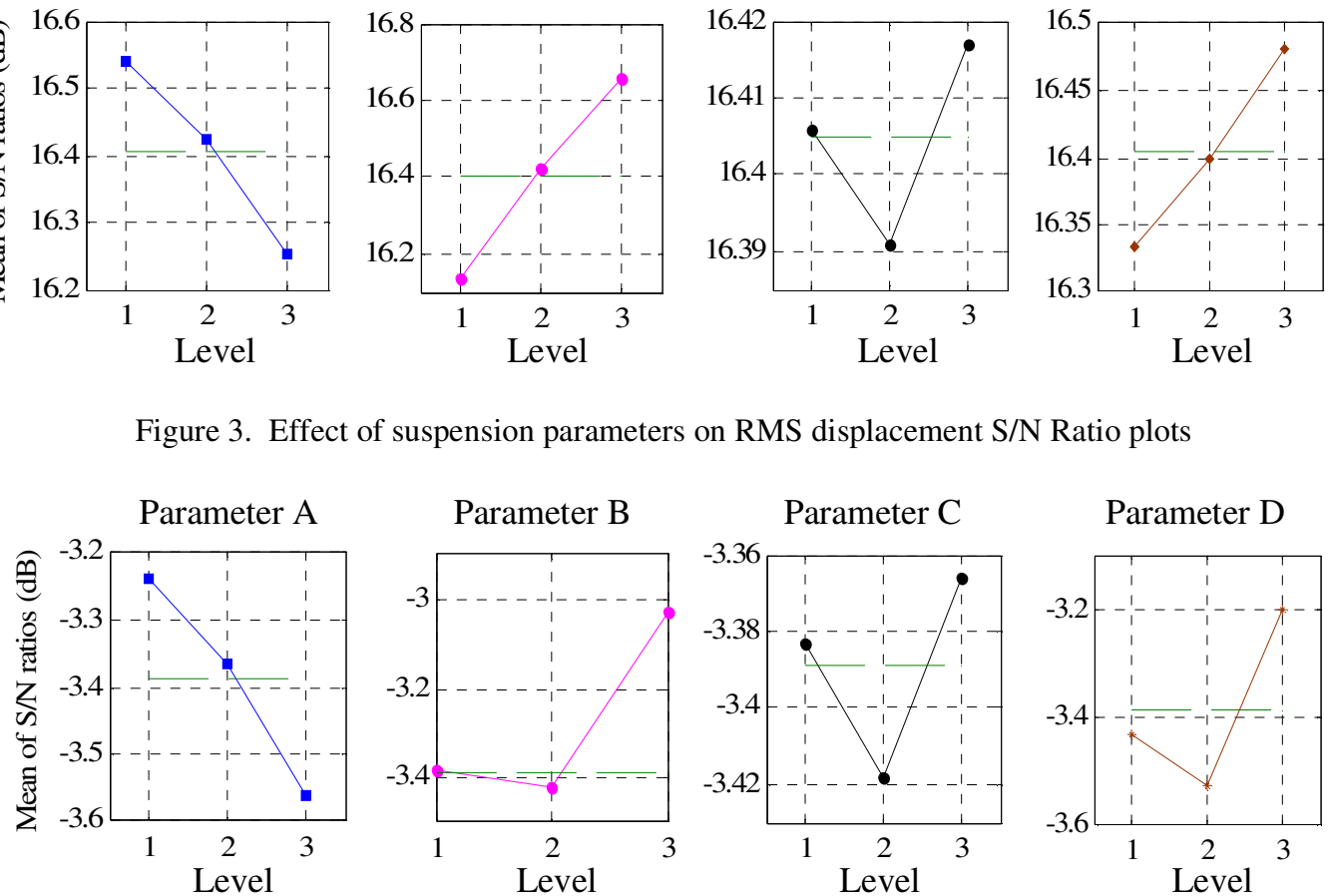

Figure 4. Effect of suspension parameters on displacement settling time S/N Ratio plots

\subsection{CONTRIBUTION OF SUSPENSION PARAMETERS ON PERFORMANCE}

ANOVA is performed to investigate which suspension parameter contributes highly in the desired performance characteristics of RMS passenger seat displacement and settling time. ANOVA results are presented in Table 5 for mean RMS PSD and in Table 6 for mean ST while bar chart for the same is shown in Figure 5. It can be seen from Table 5 that mean RMS PSD is significantly affected by parameter B with the highest percentage share of $73.01 \%$ followed by parameter A with percentage share of $21.74 \%$. From Table 6 , it can be seen that parameter B affects the mean ST with maximum percentage of $69.08 \%$ while parameter D affects the mean ST with percentage of $15.73 \%$ respectively. 
International Journal of Recent advances in Mechanical Engineering (IJMECH) Vol.4, No.1, February 2015

Table 5 ANOVA Results for mean RMS PSD (Passenger Seat Displacement)

\begin{tabular}{ccccc}
\hline Parameter & $\begin{array}{c}\text { Degree of Freedom } \\
\text { (DoF) }\end{array}$ & $\begin{array}{c}\text { Sum of Squares } \\
(\mathrm{SS})\end{array}$ & $\begin{array}{c}\text { Mean Square } \\
(\mathrm{MS})\end{array}$ & Contribution [\%] \\
\hline A & 2 & 0.0344 & 0.0172 & 21.75 \\
B & 2 & 0.1155 & 0.05775 & 73.01 \\
C & 2 & 0.0001 & 0.00005 & 0.06 \\
D & 2 & 0.0082 & 0.0041 & 5.18 \\
Error & 3 & 0 & 0 & 0.00 \\
\hline Total & 11 & 0.1582 & & 100 \\
\hline
\end{tabular}

Table 6 ANOVA Results for mean ST (Settling Time)

\begin{tabular}{ccccc}
\hline Parameter & $\begin{array}{c}\text { Degree of Freedom } \\
\text { (DoF) }\end{array}$ & $\begin{array}{c}\text { Sum of Squares } \\
\text { (SS) }\end{array}$ & $\begin{array}{c}\text { Mean Square } \\
(\mathrm{MS})\end{array}$ & $\begin{array}{c}\text { Contribution } \\
{[\%]}\end{array}$ \\
\hline A & 2 & 0.039 & 0.0195 & 15.04 \\
B & 2 & 0.1792 & 0.0896 & 69.08 \\
C & 2 & 0.0004 & 0.0002 & 0.15 \\
D & 2 & 0.0408 & 0.0204 & 15.73 \\
Error & 3 & 0 & 0 & 0.00 \\
\hline Total & 11 & 0.2594 & & 100 \\
\hline
\end{tabular}
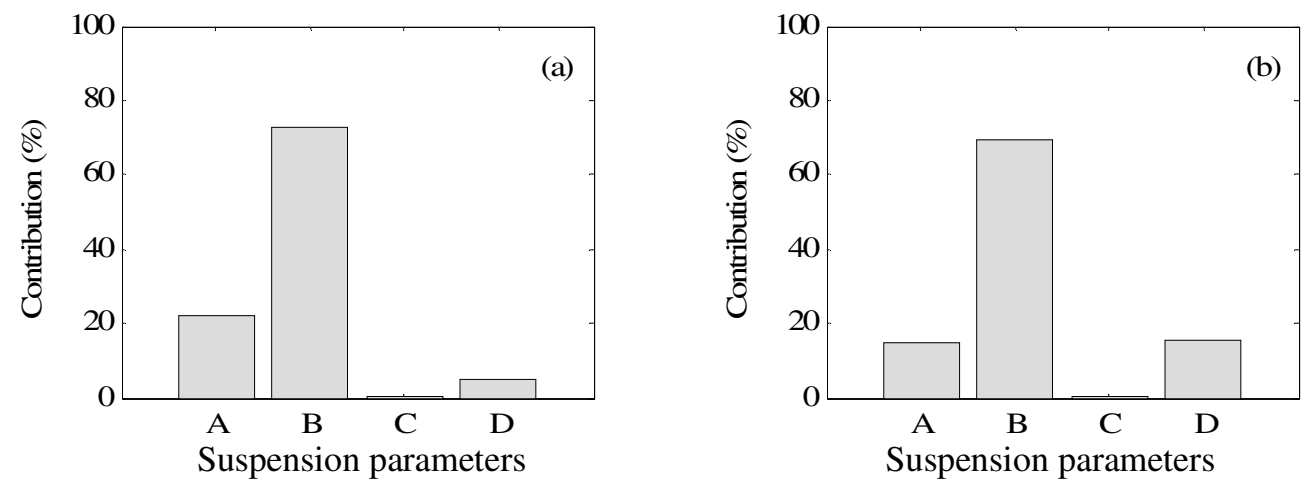

Figure 5. Percentage contribution of each factor on (a) RMS PSD (b) ST

\subsection{CONFIRMATION TEST}

Finally, after application of Taguchi method in this study, the optimum values selected for suspension parameters are tabulated in Table 7. The desired results in term of passenger ride comfort and safety can be achieved in terms of minimum RMS passenger seat displacement by the optimal mix of A1B3C3D3 (A1=26000 N/m, B3=1600 N/m/s, C3= $9400 \mathrm{~N} / \mathrm{m}, \mathrm{D} 3=900$ $\mathrm{N} / \mathrm{m} / \mathrm{s}$ ), generating a value of $0.021 \mathrm{~m}$ while the minimum passenger seat settling time value can be achieved by optimal mix of A1B3C3D3 (A1=26000 N/m, B3= $1600 \mathrm{~N} / \mathrm{m} / \mathrm{s}, \mathrm{C} 3=9400 \mathrm{~N} / \mathrm{m}$, D3 $=900 \mathrm{~N} / \mathrm{m} / \mathrm{s}$ ), providing a value of $1.850 \mathrm{sec}$ respectively. From Figure 6 (a) and (b), it can be observed that the trial no. 3 provides the lowest RMS PSD and lowest ST values. 
International Journal of Recent advances in Mechanical Engineering (IJMECH) Vol.4, No.1, February 2015

Table 7 Optimum parameter values for suspension system

\begin{tabular}{cccccc}
\hline \multirow{2}{*}{ Parameters } & \multicolumn{2}{c}{ RMS Displacement $(\mathrm{m})$} & & \multicolumn{2}{c}{ Settling time $(\mathrm{sec})$} \\
\cline { 2 - 3 } \cline { 5 - 6 } & Optimum Value & Level & & Optimum Value & Level \\
\hline $\mathrm{A}$ & 26000 & 1 & & 26000 & 1 \\
$\mathrm{~B}$ & 1600 & 3 & & 1600 & 3 \\
$\mathrm{C}$ & 9400 & 3 & & 9400 & 3 \\
$\mathrm{D}$ & 900 & 3 & & 900 & 3 \\
\hline
\end{tabular}
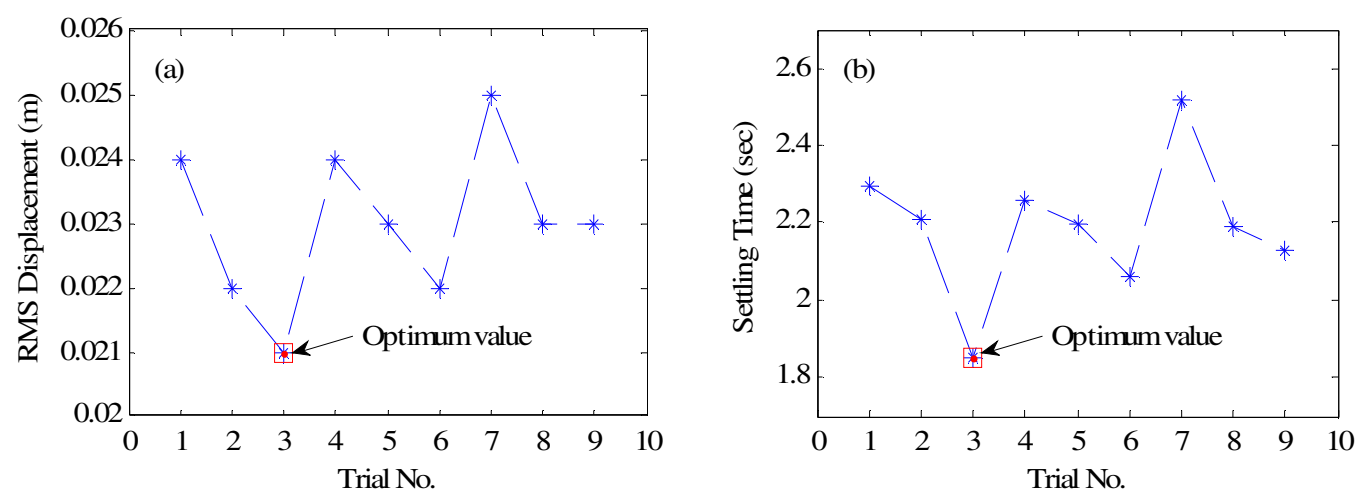

Figure 6. (a) Trail No. vs. RMS Displacement Value (b) Trial No. vs. Settling Time

\subsection{GREY RELATIONAL ANALYSIS FOR SUSPENSION SYSTEM PARAMETER OPTIMIZATION}

\subsection{GRA PROCEDURE ADOPTED}

Grey relational analysis technique is based on the concept of multi-objective optimization of considered parameters for getting best combination of input parameters by taking the experimental results. The procedure adopted to optimize the RMS PSD and ST using grey relational analysis (GRA) is as mentioned below:

1. Conversion of simulation data into $\mathrm{S} / \mathrm{N}$ values.

2. Normalize the $\mathrm{S} / \mathrm{N}$ values.

3. Calculation work related to Grey relational generating and grey relational coefficient.

4. Calculation of grey relational grade by taking the average values of the considered performance results.

5. Experimental result analysis using grey relational grade and ANOVA technique.

6. Selection of optimum levels of suspension system parameters.

7. Simulation run for the verification of optimal suspension system parameters.

\subsection{CALCULATION OF GREY RELATIONAL COEFFICIENT AND GRADE}

At initial stage, data pre-processing is performed for normalization of the simulation results in term of S/N ratios for RMS PSD and ST values within the range of zero to one, this procedure is also known as grey relational generating [23-24]. In present case, the method selected for grey 
relation computation is based on "the higher the better" type taking the values of S/N ratios and can be represented as below:

$$
x_{i}^{*}(k)=\frac{y_{i}^{0}(k)-\min \left(y_{i}^{0}(k)\right)}{\max \left(y_{i}^{0}(k)\right)-\min \left(y_{i}^{0}(k)\right)}
$$

$y_{i}^{0}(k)$ is the calculated value of the $\mathrm{S} / \mathrm{N}$ ratio, where $i=1$ to 9 and $k=1$ to 2 while $\max \left(y_{i}^{0}(k)\right)$ is the maximum value of $y_{i}^{0}(k)$ and $\min \left(y_{i}^{0}(k)\right)$ is the minimum value of $y_{i}^{0}(k)$ and $x_{i}^{*}(k)$ the grey relational grade after mathematical calculation work. The formula used for calculation of grey relational coefficient is as follows [25-26]:

$$
\xi_{i}(k)=\frac{\Delta_{\min }+\xi \cdot \Delta_{\max }}{\Delta_{o i}(k)+\xi \cdot \Delta_{\max }}, \quad 0 \leq \xi_{i}(k) \leq 1
$$

where $\Delta_{o i}(k)=\left|x_{o}^{*}(k)-x_{i}^{*}(k)\right|$ and

$\Delta_{\min }=\min \cdot \min \left(\Delta_{o i}(k)\right), \Delta_{\max }=\max \cdot \max \left(\Delta_{o i}(k)\right)$

$x_{o}^{*}(k)$ and $x_{i}^{*}(k)$ are general sequence and comparability sequence respectively. In present calculation work, the value of $\xi=0.5$ is selected. The calculated grey relational grade in Table 8 is the sum of grey relational coefficients of passenger seat RMS displacement and settling time, after performing weighted function, which is calculated using the formula as follows:

$$
g_{r}=\frac{1}{n} \sum_{i=1}^{n} \xi_{i}
$$

where $g_{r}$ is the grey relational grade, $\mathrm{r}$ is the number of simulation run and $\mathrm{n}$ is the corresponding performance characteristics which are taken as two in numbers as passenger seat RMS

\begin{tabular}{|c|c|c|c|c|c|c|}
\hline \multirow[t]{2}{*}{$\begin{array}{l}\text { Trial } \\
\text { No. }\end{array}$} & \multicolumn{2}{|c|}{$\begin{array}{c}\text { Normalized S/N } \\
\text { Ratio }\end{array}$} & \multicolumn{2}{|c|}{$\begin{array}{l}\text { Grey relational } \\
\text { coefficients after } \\
\text { weighted }\end{array}$} & \multicolumn{2}{|c|}{$\begin{array}{l}\text { Grey relational } \\
\text { grade }\end{array}$} \\
\hline & RMS PSD & ST & RMS PSD & ST & Grey Grade & Rank \\
\hline 1 & 0.2366 & 0.2966 & 0.3958 & 0.4155 & 0.4057 & 8 \\
\hline 2 & 0.6138 & 0.4247 & 0.5642 & 0.465 & 0.5146 & 3 \\
\hline 3 & 1 & 1 & 1 & 1 & 1 & 1 \\
\hline 4 & 0.2567 & 0.3483 & 0.4022 & 0.4341 & 0.4182 & 7 \\
\hline 5 & 0.4431 & 0.4382 & 0.4731 & 0.4709 & 0.472 & 6 \\
\hline 6 & 0.7701 & 0.6494 & 0.685 & 0.5878 & 0.6364 & 2 \\
\hline 7 & 0 & 0 & 0.3333 & 0.3333 & 0.3333 & 9 \\
\hline 8 & 0.4007 & 0.4539 & 0.4548 & 0.478 & 0.4664 & 5 \\
\hline 9 & 0.4855 & 0.5476 & 0.4928 & 0.525 & 0.5089 & 4 \\
\hline
\end{tabular}
displacement and settling time respectively.

Table 8 Normalized $\mathrm{S} / \mathrm{N}$ ratio run results

Figure 7 shows the linear graph for the variation of grey relational grade for different combinations of nine simulation runs. Basically, larger value of grey relational grade is desired, 
since it favors the selection of suspension parameters to achieve the optimum / best results. The mean values of grey relational grade related to suspension parameters are calculated for each level as listed in Table 9. Figure 7 shows that both the desired characteristics/ results of quarter car simulation response are significantly dependent on the selected suspension parameters. It can be seen from Table 8 that trial No. 3 has the maximum value of grey relational grade providing the best multiple performance characteristics.

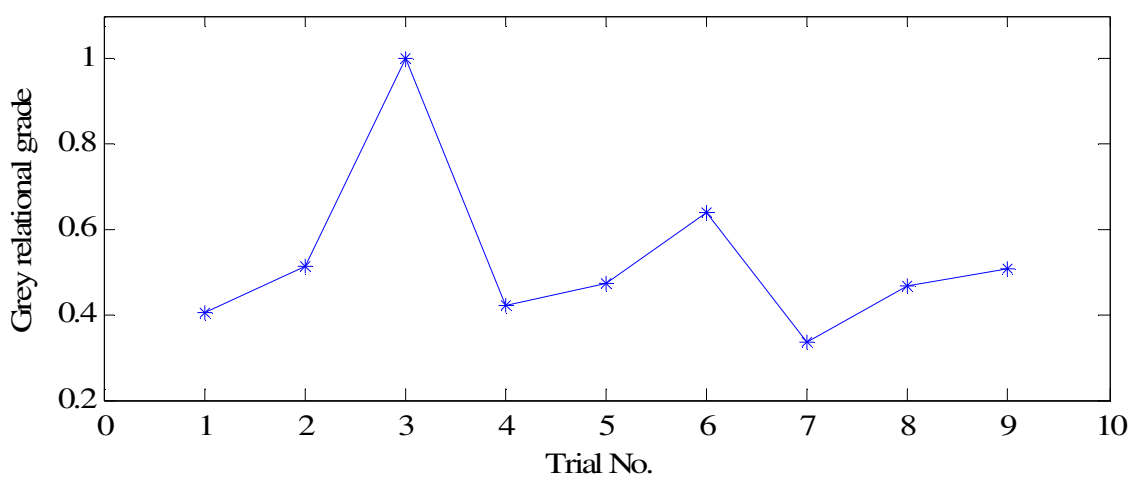

Figure 7. Grey relational grade for minimum passenger seat displacement and settling time

The calculated average grey relational grade for each suspension parameter and corresponding levels is shown in Table 9. Based on these calculations, effect of each suspension parameter in combination with their levels is plotted separately as shown in Figure 8. Larger grey relational grade supports the best combination of individual parameters out of various choices. As seen from Figure 8, the combination of $\mathrm{A} 1 \mathrm{~B} 3 \mathrm{C} 3 \mathrm{D} 3$ shows the maximum value of grey relational grade for each suspension parameter and levels respectively. Therefore A1 $(26000 \mathrm{~N} / \mathrm{m}), \mathrm{B} 3(1600$ $\mathrm{N} / \mathrm{m} / \mathrm{s}), C 3(9400 \mathrm{~N} / \mathrm{m})$ and D3 $(900 \mathrm{~N} / \mathrm{m} / \mathrm{s})$ are the optimal combination of suspension parameters for multi-suspension characteristics for semi-active quarter car model as tabulated in Table 10.

Table 9 Response table for grey relational grade

\begin{tabular}{cccccc}
\hline & \multicolumn{4}{c}{ Level } & \\
\cline { 2 - 4 } Parameters & 1 & 2 & 3 & & \\
\hline A & 0.6401 & 0.5088 & 0.4361 & 0.204 & 2 \\
B & 0.3856 & 0.4843 & 0.7151 & 0.3295 & 1 \\
C & 0.5028 & 0.4806 & 0.6017 & 0.1211 & 4 \\
D & 0.4622 & 0.4946 & 0.6282 & 0.166 & 3 \\
\hline
\end{tabular}
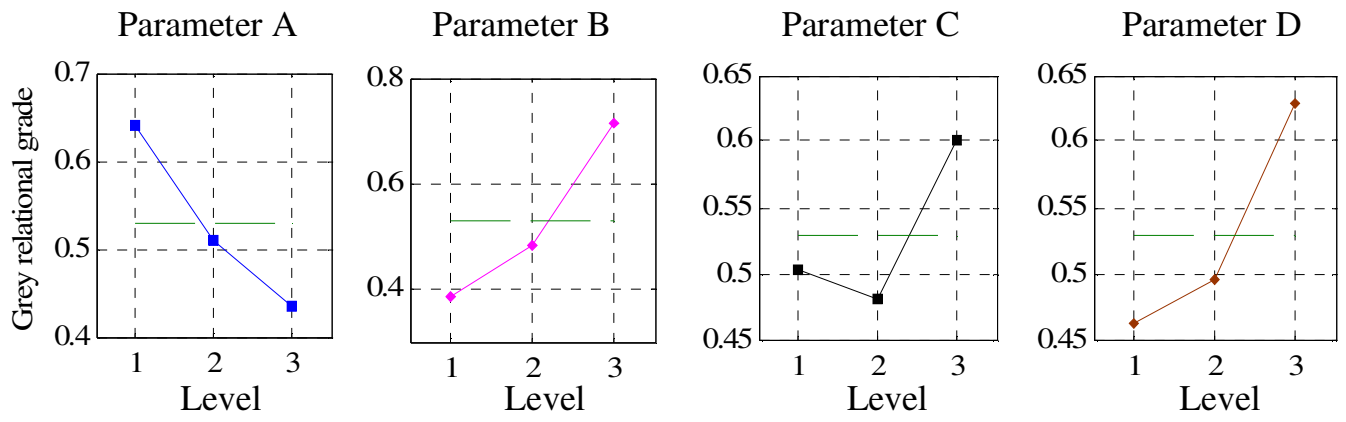

Figure 8. Grey relational grade for minimum passenger seat displacement and settling time. 
International Journal of Recent advances in Mechanical Engineering (IJMECH) Vol.4, No.1, February 2015

Table 10 Optimum parameter values for suspension system

\begin{tabular}{cccccc}
\hline \multirow{2}{*}{ Parameters } & \multicolumn{2}{c}{ RMS Displacement $(\mathrm{m})$} & & \multicolumn{2}{c}{ Settling time $(\mathrm{sec})$} \\
\cline { 2 - 3 } \cline { 5 - 6 } & Optimum Value & Level & & Optimum Value & Level \\
\hline $\mathrm{A}$ & 26000 & 1 & & 26000 & 1 \\
$\mathrm{~B}$ & 1600 & 3 & & 1600 & 3 \\
$\mathrm{C}$ & 9400 & 3 & & 9400 & 3 \\
$\mathrm{D}$ & 900 & 3 & & 900 & 3 \\
\hline
\end{tabular}

\subsection{CONTRIBUTION OF SUSPENSION PARAMETERS ON PERFORMANCE}

ANOVA is performed by taking the grey relational grade of simulation result sequence (Table 8) to study the level of influence/ importance of each suspension parameter on desired performance of quarter car system. The mathematical values of calculated important quantities helpful in decision making are shown in Table 11 and same is presented in bar chart form in Figure 9. From the ANOVA results in Table 11, it can be seen that B influences the passenger seat displacement and settling time with the maximum percentage share of $55.88 \%$ whereas A's contribution lies at second stage with percentage share of $20.89 \%$ while D and C influence the desired results with $15.12 \%$ and $8.11 \%$ respectively.

Table 11 ANOVA for multiple performance characteristics

\begin{tabular}{ccccc}
\hline Parameter & $\begin{array}{c}\text { Degree of } \\
\text { Freedom }(\text { DoF })\end{array}$ & $\begin{array}{c}\text { Sum of } \\
\text { Squares (SS) }\end{array}$ & $\begin{array}{c}\text { Mean Square } \\
(\mathrm{MS})\end{array}$ & Contribution [\%] \\
\hline A & 2 & 0.0641 & 0.03205 & 20.89 \\
B & 2 & 0.1715 & 0.08575 & 55.88 \\
C & 2 & 0.0249 & 0.01245 & 8.11 \\
D & 2 & 0.0464 & 0.0232 & 15.12 \\
Error & 3 & 0 & 0 & 0.00 \\
\hline Total & 11 & 0.3069 & & 100 \\
\hline
\end{tabular}

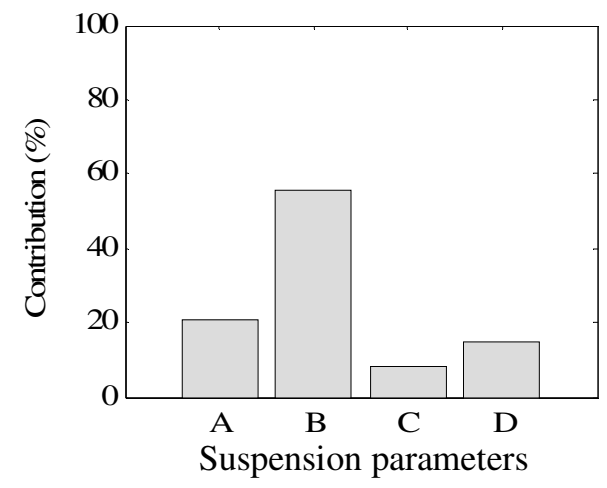

Figure 9. Percentage contribution of each factor 


\subsection{CONFIRMATION TEST}

Once the optimal levels and their related mathematical values of suspension parameters are known, then final step includes testing the system performance with these parameter values. Simulation run is performed under the combination of optimal values of suspension parameters, namely, A1, B3, C3 and D3, to obtain the results in terms of RMS passenger seat displacement and settling time respectively for comparison purpose. Table 12 lists the final results for optimum combination (A1, B3, C3 and D3) and initially selected (A1, B1, C1 and D1) suspension parameters. It can be observed that the desired performance in terms of passenger ride comfort has improved using optimum combination of suspension parameters as obtained by GRA method.

Table 12 Comparative data between initial and optimal level suspension parameters

\begin{tabular}{lccc}
\hline & \multicolumn{2}{c}{ Parameter combination } & \multirow{2}{*}{ Improvement } \\
\cline { 2 - 3 } & Initial design & Optimal design & \\
\hline Setting Level & A1B1C1D1 & A1B3C3D3 & \\
Displacement (m) & 0.024 & 0.021 & $12.5 \%$ \\
Settling Time (sec) & 2.296 & 1.850 & $19.42 \%$ \\
Grey relational grade & 0.4057 & 1 & $59.43 \%$ \\
\hline
\end{tabular}

\section{SUMMARY OF RESULTS}

In first phase, Taguchi method was used to optimize the suspension parameter settings for RMS passenger seat displacement and settling time values separately. While in second phase, multiple characteristic optimizations of suspension parameters were obtained successfully using GRA method. Application of ANOVA method indicates that two process parameters namely, primary suspension damping (B) and primary suspension stiffness (A) contribute significantly in both methods used in present study i.e. Taguchi and GRA method. The calculated optimized parameters setting combination that can provide best ride comfort to travelling passengers in quarter car system for individual and multiple suspension characteristics is shown in Table 13. The simulation results by putting the optimal values in quarter car model in terms of passenger seat displacement is shown in Figure 10 (a) while the desired damping force signal generated by assembled MR shock absorber in primary suspension system and passive shock absorber in secondary suspension system is shown in Figure 10 (b)-(c).

Table 13 Summary of results

\begin{tabular}{|l|l|c|c|}
\hline Optimization technique & \multicolumn{1}{|c|}{ Method } & $\begin{array}{c}\text { Optimal parameters } \\
\text { combination }\end{array}$ & Optimal results \\
\hline Taguchi method & $\begin{array}{l}\text { Individual parameter } \\
\text { optimization }\end{array}$ & A1B3C3D3 & $\begin{array}{l}\text { RMS PSD }=0.021 \mathrm{~m} \\
\mathrm{ST}=1.850 \mathrm{sec}\end{array}$ \\
\hline Grey relational analysis & $\begin{array}{l}\text { Multiple parameter } \\
\text { optimization }\end{array}$ & A1B3C3D3 & $\begin{array}{c}\text { RMS PSD }=0.021 \mathrm{~m} \\
\mathrm{ST}=1.850 \mathrm{sec}\end{array}$ \\
\hline
\end{tabular}



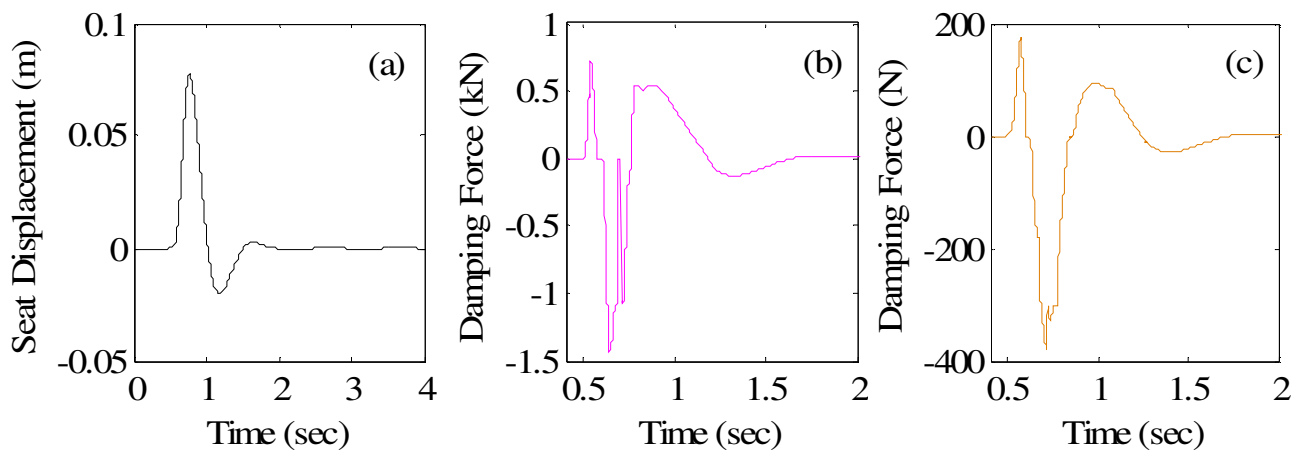

Figure 10. (a) Passenger seat displacement, (b) desired damping force signal generated by MR shock absorber in primary suspension system, (c) desired damping force signal generated by passive shock absorber in secondary suspension system

\section{CONCLUSIONS}

In present work, optimization of primary as well as secondary suspension parameters of quarter car model having three degrees of freedom is studied using Taguchi and Grey Relational Analysis separately using simulation results. Based on the optimized results in terms of RMS passenger seat displacement and settling time values, following conclusions can be made from the study:

1. Taguchi method was used to optimize RMS PSD and ST individually. The optimal setting found for both the desired results is A1B3C3D3 with the optimal values of $0.021 \mathrm{~m}$ for RMS PSD and $1.850 \mathrm{sec}$ for ST respectively. Application of ANOVA technique shows that there are mainly two suspension parameters such as primary suspension damping (A) and primary suspension stiffness (B), responsible for high contribution in achieving the lower values of RMS PSD while primary suspension damping (A) and secondary suspension damping (D) are contributing highly in achieving the lower values of ST.

2. GRA method was helpful in achieving the optimum combination of suspension parameters for multiple suspension characteristics based on the steps followed in this method in terms of normalization of $\mathrm{S} / \mathrm{N}$ ratios, weighted grey relational coefficients and grey relational grade respectively. Using ANOVA technique based on grey relational grade data, primary suspension damping (A) and primary suspension stiffness (B) were found responsible for high contribution in performance of quarter car model related to passenger ride comfort.

3. It can be concluded that using Taguchi and GRA method for simultaneous optimization of suspension parameters, the optimum combination of suspension parameters was found to be A1B3C3D3 in both the cases. Thus the results and procedures adopted for optimization of suspension parameters will be useful for automotive manufacturers in selection of best possible combination of suspension parameters to achieve desired ride comfort and safety to travelling passengers.

\section{REFERENCES}

[1] J.G. Stein, P. Mucka, and T.P. Gunston (2009) "A study of locomotive driver's seat vertical suspension system with adjustable damper”, Vehicle System Dynamics, Vol. 47, No. 3, pp. 363-386.

[2] I. Hostens, K. Deprey, and H. Ramon (2004) "An improved design of air suspension for seats of mobile agricultural machines", Journal of Sound and Vibration, Vol. 276, No. 1-2, pp. 141-156. 
[3] M. Bouazara and M.J. Richard (1996) "An optimal design method to control the vibrations of suspensions for passenger cars", International Mechanical Engineering Congress and Exposition: The Winter Annual Meeting of ASME, Atlanta, DSC 58, pp. 61-68.

[4] R.M. Goodall, and W. Kortüm (1983) "Active control in ground transportation - a review of the stateof-the-art and future potential", Vehicle System Dynamics, Vol. 12, pp. 225-257.

[5] M. Ahmadian, X. Song, and S.C. Southward (2004) "No-jerk skyhook control methods for semi active suspensions", Journal of Vibration and Acoustics, Vol. 126, No. 4, pp. 580-584.

[6] E. Guglielmino, T. Sireteanu, C.W. Stammers, G. Ghita and M. Giuclea (2008) "Semi-active Suspension Control : Improved Vehicle Ride and Road Friendliness", Springer, Springer-Verlag, London.

[7] S. Sassi, K. Cherif, L. Mezghani, M. Thomas, M., and A. Kotrane (2005) "An innovative magnetorheological damper for automotive suspension: from design to experimental characterization", Smart Mater. Struct. Vol. 14, pp. 811-822.

[8] Q.H. Nguyen and S.B. Choi (2009) "Optimal design of MR shock absorber and application to vehicle suspension”, Smart Mater. Struct., Vol. 18, No. 3, 035012.

[9] C.C. Chang and P. Roschke (1998) "Neural network modeling of a magnetorheological damper", J. Intell. Mater. Syst. Struct., Vol. 9, pp. 755-64.

[10] H. Du, J. Lam, and N. Zhang (2006) "Modeling of a magneto-rheological damper by evolving radial basis function networks", Eng. Appl. Artif. Intell., Vol. 19, pp. 869-81.

[11] K.C. Schurter, and P.N. Roschke (2000) "Fuzzy modeling of a magnetorheological damper using ANFIS”, Proc. IEEE Int. Conf. on Fuzzy Systems, pp. 122-7.

[12] G. Jin, M. K. Sain, K.D. Pham. F.S. Jr Billie, and J.C. Ramallo (2001) "Modeling MR-dampers: a nonlinear blackbox approach", Proc. American Control Conf., 1, pp. 429-34.

[13] A. Leva, and L. Piroddi (2002) "NARX-based technique for the modelling of magneto-rheological damping devices", Smart Mater. Struct., Vol. 11, pp. 79-88.

[14] Devdutt, and M.L. Aggarwal (2012) "Fuzzy Control of Seat Vibrations for Semi-Active Quarter Vehicle System Utilizing Magneto rheological Damper", International Journal of Engineering Inventions, Vol. 1, No. 12, pp. 51-56.

[15] A.F. Naude and J.A. Snyman (2003) "Optimisation of road vehicle passive suspension systems. Part 2. Qualification and case study”, Applied Mathematical Modelling, Vol. 27, pp. 263-274.

[16] Anil Shirahatt, P.S.S. Prasad, and M.M. Kulkarni (2008) "Optimal Design of Passenger Car Suspension for Ride and Road Holding” J. of the Braz. Soc. of Mech. Sci. \& Eng., Vol. XXX, No. 1, pp.66-77.

[17] P.Senthil kumar, R.Kalidas, K.Sivakumar, E.Hariharan, B.Gautham and R. Ethiraj (2013) "Application of Taguchi method for optimizing passenger-friendly vehicle suspension system", International Journal of Latest Trends in Engineering and Technology, Vol. 2, Issue 1, pp. 133-141.

[18] R.Kalidas, P.Senthil kumar, S.Vinoth Sarun (2013) "Mathematical Modeling And Optimization Of Vehicle Passive Suspension System Using Full Car Model”, International Journal of Innovative Research \& Development, Vol 2, Issue 2, pp. 366-382.

[19] W.H. Wang, and Y.S. Tarng (1998) "Design optimization of cutting parameters for turning operations based on the Taguchi method", Journal of Material Processing Technology, Vol. 84, pp. 122-129.

[20] B.H. Lee, J. Abdullah, and Z.A. Khan (2005) "Optimization of rapid prototyping parameters for production of flexible ABS object”, Journal of material Processing Technology, Vol. 169, pp. 54-61.

[21] J. Laeng, Z.A. Khan and S.Y. Khu (2006) "Optimizing flexible behaviour of bow prototype using Taguchi approach", Journal of Applied Sciences, Vol. 6, pp. 622-630.

[22] S. Kamaruddin, Z.A. Khan, and K.S. Wan (2004) "The use of the Taguchi method in determining the optimum plastic injection moulding parameters for the production of a consumer product", Jurnal Mekanikal, Vol. 18, pp. 98-110.

[23] C. C. Tsao (2009) "Grey -Taguchi method to optimize the milling parameters of aluminum alloy", International Journal of Advanced Manufacturing Technology, Vol. 40, pp. 41-48.

[24] Nihat Tosun (2006) "Determination of optimum parameters for multi-performance characteristics in drilling by using grey relational analysis", International Journal of Advanced manufacturing Technology, Vol. 28, pp. 450-455.

[25] J.L. Deng (1989) "Introduction to grey system theory", J. Grey System, Vol. 1, pp. 1-24.

[26] Z.C. Lin and C.Y. Ho (2003) "Analysis and application of grey relation and ANOVA in chemicalmechanical polishing process parameters”, Int. J. Adv. Manufacturing Technology, Vol. 21, pp. 1014. 


\section{Authors}

Devdutt is PhD student in the Department of Mechanical Engineering, YMCA University of Science and Technology, Faridabad, Haryana, India. Presently he is working as Assistant Professor in the Department of Mechanical Engineering, Faculty of Engineering and Technology, Manav Rachna International University, Faridabad, Haryana, India. His research areas of interest are noise, vibration and ride quality related to semi-active and active vehicle suspension system.

Dr. M.L.Aggarwal has done B.Sc. (Mechanical Engg.) from REC Kurukshetra, Haryana, India in 1988, M.Tech. and Ph.D. from IIT New Delhi in 2003 and JMI New Delhi in 2007 respectively. He has been working in YMCA University of Science \& Technology Faridabad, Haryana, India since 1989. He has published 40 papers in International / National Journals in the relevant areas of design engineering. His research areas of interest

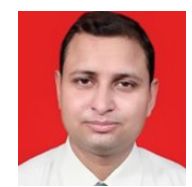
are materials, shot peening and design. 